\title{
Maternal Health in Pakistan: Where do we stand?
}

\author{
Farah Rashid ${ }^{1}$, Sara Makhdoom² \\ ${ }^{1}$ Professor and Head, Department of Community Medicine, Islamabad Medical and Dental College \\ ${ }^{2}$ Fellow of College of Family Physicians, Canada
}

Pakistan ranked amongst sixth most populous country in the world given the current rates; it will be the fifth most populous country globally by $2050 .{ }^{1}$ This rapid population growth leads to poor literacy and high fertility which translates into high morbidity and mortality, where women being the most vulnerable fragment in health especially. ${ }^{1,2}$

Maternal mortality and morbidity are a major challenge that shows health inequalities and social injustice. In this modern era of medicine, almost all maternal deaths should have been prevented. Pakistan is one of the six countries which together contribute to $50 \%$ of global maternal deaths. ${ }^{2}$ High maternal mortality $(177 / 100,000$ live births) in Pakistan indicates neglect of women health as well as in-effective and insufficient obstetric services at the primary care level. ${ }^{3}$

The most significant approach to improve maternal health involves training and availability of skilled birth attendant in both public and private sector. Data retrieved from developing countries show that only $44 \%$ of deliveries in rural areas and $75 \%$ in urban areas were attended by skilled personnel. ${ }^{4}$

World Bank in 2015 reported a negligible maternal mortality ratio in developed countries. These include $3 / 100,000$ live births in Greece, 4/100,000 in Austria, $5 / 100,000$ in Japan, 6/100,000 in Germany, 7/100,000 in Canada, and 9/100,000 live births in UK, respectively. ${ }^{5}$

Now question arises what miracle industrialized world has done to achieve the optimum level of maternal health. Research shows $\mathrm{MNCH}$ has been a priority public health problem for decades. Since 1990's, the industrialized nation has adopted important strategies to reduce maternal and childhood morbidity and mortality, ${ }^{6}$ these are in line with the renewed Global Strategy for Women's, Children's and Adolescents' Health (2016-2030). ${ }^{6}$
Initially the main initiative has focused on access to health care services and enhancing the number of births in health facilities, at the same time increasing the births attended by skilled health care professionals. Moreover, access to vibrant Primary Health Care with wellestablished and effective linkages with tertiary care services for provision of quality obstetric care at the time of need, thus giving importance to the quality of care received. ${ }^{7}$

In Pakistan, Lady Health Worker Program (LHWP), was launched during early 1990s, with community involvement and awareness regarding basic issues of health and family planning. This program strengthened the primary care facility and had significantly improved Maternal Neonatal, and Child Health (MNCH) status., ${ }^{2,3}$ According to a recent survey in Pakistan, $86 \%$ of women received antenatal care from a skilled provider, $51 \%$ of women had at least four antenatal care visits, $69 \%$ women were protected against neonatal tetanus, $69 \%$ of deliveries were conducted by skilled birth attendants, and $66 \%$ of deliveries took place in a health facility. ${ }^{3}$

In spite of all these efforts, Pakistan was held up behind in achieving the health-related Millennium Development Goals (MDGs), ${ }^{7}$ particularly Goals 4 and 5 . Being a signatory of the Sustainable Development Goals (SDGs) 2015-2030, which would need even greater efforts than those employed for the MDGs, the Government of Pakistan developed a monitoring and evaluation mechanism for the National Health Vision 2016-2025. The resulting agenda and plan is linked and collaborated with the Planning Commission of Pakistan for SDG reporting, through a hierarchy based reporting system which is fed by the provincial and local health departments for translation of policies to action. ${ }^{8}$ 
The urge to improve maternal, newborn and child health in Pakistan is only fulfilled successfully when the senior leadership is mindful about the significance of these investments for national progress. Moreover evidence shows the key to success is provision of timely quality obstetric care through empathetic and compassionate health care professionals. ${ }^{6,8}$

It is a serious matter that requires urgent attention and action through concentrated and direct efforts, enhancing multi-sectoral collaboration, acquiring commitment from the elected representatives, the civil society, researchers, clinicians and public health experts. All stakeholders will have to play a significant role in improving the current maternal health situation in the country.

\section{References}

1. National Institute of Population Studies. Population projections, 2015. http://www.nips.org.pk/news_details.php?news=MjE

2. Syeda Batool Mazhar. Obstetric Services in Pakistan: Where are we and what is the way forward? RMJ. 2013; 38(1): $1-2$.
3. National Institute of Population Studies (NIPS) [Pakistan] and ICF. 2019. Pakistan Demographic and Health Survey 2017-18. Islamabad, Pakistan, and Rockville, Maryland, USA: NIPS and ICF.

4. Pakistan Demographic and Health Survey (preliminary report), Federal Bureau of Statistics, Statistics Division, 2012-13.

5. WHO, UNICEF, "UNFPA, World Bank Group and United Nation Population Division. Trends in maternal mortality: 1990-2015. Estimates by WHO, UNICEF." (2015): 599-620. URL: data.worldbank.org/indicator/sh.sta.mmrt

6. World Health Organization. The global strategy for Women's, Children's and adolescents' health (2016 - 2030). United Nations. 2015. http://www.who.int/lifecourse/partners/global-strategy/ewec-globalstrategyreport200915.pdf?ua=1.

7. Millennium Development Goals Database: Goal 5. Improved Maternal Health Statistics Pakistan. (Online) 2013 URL: http://data.un.org.html.

8. Government of Pakistan. 2016a. National Health Vision Pakistan. 2016-2025 http://www.nationalplanningcycles.org/sites/default/files/plan ning_cycle_repository/pakistan/national_health_vision_201 6-25_30-08-2016.pdf. 